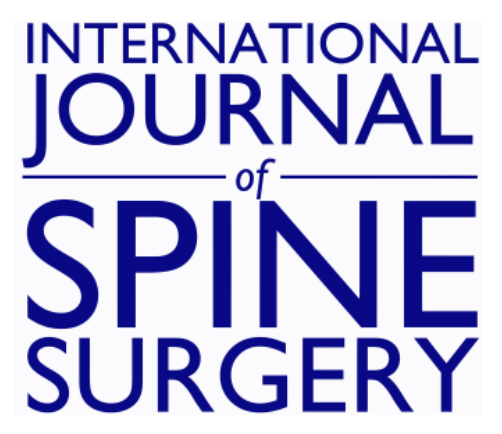

\title{
Temporal Pattern of Pain and Disability Following the Administration of a Selective Nerve Root Block in Lumbar Disc Herniation With Radiculopathy
}

Hamza Shaikh, Apoorv Kumar and Thomas J. Kishen

Int J Spine Surg 2021, 15 (6) 1090-1095

doi: https://doi.org/10.14444/8195

http://ijssurgery.com/content/15/6/1090

This information is current as of April 26, 2023.

Email Alerts Receive free email-alerts when new articles cite this article. Sign up at:

http://ijssurgery.com/alerts

The International Journal of Spine Surgery

2397 Waterbury Circle, Suite 1,

Aurora, IL 60504, Phone: +1-630-375-1432 


\title{
Temporal Pattern of Pain and Disability Following the Administration of a Selective Nerve Root Block in Lumbar Disc Herniation With Radiculopathy
}

\author{
HAMZA SHAIKH, FNB ${ }^{1}$; APOORV KUMAR, FNB $^{1}$; AND THOMAS J. KISHEN, FRCS ${ }^{1}$ \\ ${ }^{I}$ Spine Care Centre, Manipal Hospital, Bangalore, India
}

\begin{abstract}
Background: Lumbar disc herniation with radiculopathy has a favorable natural history, and a selective nerve root block (SNRB) is an accepted treatment modality. This study aims to ascertain the temporal pattern of pain and disability following the administration of an SNRB in the management of lumbar disc herniation with radiculopathy because there is limited evidence regarding this issue in the published literature.

Methods: This prospective study included 50 patients who underwent an SNRB and were followed for 3 months. Numerical Rating Scale (NRS) for back and leg pain and Oswestry Disability Index (ODI) and Depression Anxiety Stress Scales-21 (DASS-21) scores were collected. At the final follow-up at 3 months, the number of patients who underwent surgery was ascertained.

Results: Forty-two of $50(84 \%)$ patients avoided the surgery with a reduction in mean preinjection NRS for back and leg pain from 7.5 (SD 1.33) and 7.7 (SD 1.35) to 3.1 (SD 1.69) and 2.3 (SD 1.14) $(P<0.001)$, respectively, within the 30 minutes after injection. The pain relief was sustained until the last follow-up. The ODI score also decreased from a mean preinjection level of 59.4 (SD 14.69) to 26.3 (SD 9.43) $(P<0.001)$ at 3 months. The mean preinjection depression score was higher in patients who had recurrence of pain and eventually underwent surgery.

Conclusion: Early administration of an SNRB in the course of lumbar radiculopathy is recommended as it provides instantaneous and sustained relief of back and leg pain and disability in a majority of patients.

Clinical Relevance: SNRB should be administered early in the course of management of lumbar radiculopathy and should not be delayed until after other non-surgical modalities have failed.

Level of Evidence: 2.
\end{abstract}

Lumbar Spine

Keywords: lumbar disc herniation, lumbar radiculopathy, transforaminal steroid injection, selective nerve root block

\section{INTRODUCTION}

The favorable natural history of lumbar radiculopathy was enunciated many centuries ago by Hippocrates, who, despite not recognizing the source of the problem, noted that the symptoms of lumbar radiculopathy subside in 40 days with rest and hot massage. ${ }^{1}$ However, the cause-effect relationship between lumbar disc herniation and radicular leg pain was established by Mixter and Barr only in $1934 .^{2}$ The current management of lumbar disc herniation causing radiculopathy is short-term rest, analgesics/medications, physiotherapy, and SNRB/transforaminal steroid injections, with surgery being reserved for those with recalcitrant symptoms, significant neurological deficits, or cauda equina syndrome. A majority of patients report symptomatic improvement with nonsurgical treatment and return to work within 6 weeks (as mentioned by Hippocrates).${ }^{3,4}$ Although the role of selective lumbar nerve root block in the management of lumbar radicular pain has been established, ${ }^{5,6}$ there is limited evidence regarding the temporal pattern of improvement in radicular pain and associated disability and whether the injections can alter the natural history of lumbar radiculopathy and obviate the need for surgery. ${ }^{7-10}$

The objective of this study was to examine the temporal pattern of change in pain intensity and disability associated with lumbar disc herniation with radiculopathy and whether surgery could be avoided by the administration of an SNRB. The effect of depression, anxiety, and stress on the outcome of SNRB was also analysed.

\section{MATERIALS AND METHODS}

This is a prospective study of 50 patients who presented to our hospital with radicular leg pain from a lumbar disc herniation and underwent a single SNRB between September 2017 and September 2018. Patients 
older than 18 years with radicular leg pain and magnetic resonance imaging scan evidence of lumbar disc herniation were included in the study. However, patients presenting with progressive/significant motor deficits in the lower limbs, cauda equina syndrome, trauma, tumors/metastatic lesions, and spinal infection were excluded from the study. In addition, those with a lack of correlation between clinical and magnetic resonance imaging findings and known allergy to local anesthetic agents or steroids were also excluded from the study. All patients were followed up for 3 months.

Pain and disability were assessed using the NRS score and ODI score, respectively, before the injection, immediately after the injection (within $30 \mathrm{~min}$ ), and at regular intervals ( 1 week, 3 weeks, and 3 months) thereafter. The DASS-21 questionnaire was administered before the injection to assess patients' stress, anxiety, and depression levels. At final follow-up (3 months), the number of patients who underwent surgery was recorded.

\section{Drugs Used for Nerve Root Block}

1. Inj. Xylocaine (2\%): For local anesthesia of overlying skin

2. Inj. Bupivacaine $(0.25 \%)$ (preservative free): Long-acting local anesthetic agent for nerve root block

3. Inj. Triamcinolone $(1 \mathrm{~mL} / 40 \mathrm{mg})$ : Long-acting steroid for nerve root block

The SNRB was administered in the operation theater with the patient prone and using a spinal needle (gauge: $22 \mathrm{G} \times 90 \mathrm{~mm}$ ). The starting point on the skin is 4 fingers breadths lateral to midline and approximately midway between the 2 adjacent transverse processes and directed toward the foramen. After administering 3-4 mL of local anesthetic ( $2 \%$ Xylocaine), the spinal needle is advanced to the corresponding pars interarticularis under fluoroscopic guidance and then slides underneath it. The needle is placed in the safe "triangle," bordered by the base of the superior pedicle above, the outer vertical border of the intervertebral foramen laterally, and the connecting diagonal nerve root and dorsal ganglion medially. The tip of the needle lies above and lateral to the exiting nerve root in the foramen. ${ }^{11,12}$ The medications (Bupivacaine and steroid) are administered after fluoroscopic confirmation of the needle position in the anteroposterior and lateral view, that is, middle of the foramen in the lateral view and below the pedicle (but not crossing the midline) in the anteroposterior view. We used only anteroposterior and lateral fluoroscopy images to confirm the needle position and did not use a dye. The $\mathrm{S} 1$ nerve root is targeted by inserting the needle under fluoroscopic guidance into the first dorsal sacral foramina (but not beyond half the anterior posterior width of the sacrum in the lateral view) where $\mathrm{S} 1$ root exits.

\section{Postinjection Protocol}

- The injection was performed as an outpatient procedure and patients were allowed to go home after the injection.

- Patients were cautioned about the possibility of numbness and weakness in the legs and advised to stay at home for the rest of the day.

- Diabetic patients were cautioned about a transient increase in blood sugar levels and advised to monitor blood sugar levels for the first 3 days.

- Tablet Pregabalin 75 mg every night was advised for 3 weeks.

- Patients were advised to avoid strenuous activity but absolute bed rest was not recommended.

- No physiotherapy or exercises was advised.

- Patients were advised to resume daily activities and to return to work when pain permits.

- Questionnaires were administered immediately after the injection (within $30 \mathrm{~min}$ ) and at 1 week, 3 weeks, and 3 months thereafter.

\section{Data Collection}

The data were entered using Excel 2007 (Microsoft Corporation, Seattle, WA, USA) and analysis was performed using $\mathrm{R}$ software version 3.2.3. Continuous variables were represented by the mean and standard deviation and categorical variables were summarized as frequency. Wilcoxon Signed Ranks test was used to compare the NRS (back and leg pain) and ODI between preinjection scores and at subsequent follow-up visits.

\section{RESULTS}

\section{Effect of SNRB on the Need for Surgery}

Fifty patients who underwent an SNRB and followed prospectively for 3 months were included in the study. Forty-two out of 50 patients (84\%) had significant relief of pain and opted not to undergo surgery while the remaining 8 patients underwent surgery before completion of 3 months (Table 1). Out of 8 patients, 4 underwent surgery within 1 to 2 weeks of the injection, while the remaining 4 underwent surgery after 3 weeks of the injection. 
Table 1. Effect of nerve root block on the need of the surgery by patient sex $(N=50)$.

\begin{tabular}{lccc}
\hline & \multicolumn{2}{c}{ Surgery Avoided } & \\
\cline { 2 - 3 } Patient Sex & Yes & No & Total \\
\hline Female & $13(38.1 \%)$ & $2(25.0 \%)$ & 15 \\
Male & $29(69.9 \%)$ & $6(75.0 \%)$ & 35 \\
Total & 42 & 8 & 50 \\
\hline
\end{tabular}

The patients who avoided surgery had a median age of 43 years (range, 19-69 years) while the median age of patients who underwent surgery was 36 years (range, 27-72 years) and the median duration of symptoms before undergoing the injection was 14 days (range, 1-60 days) and 15 days (range, 7-30 days), respectively (Table 2). There was no significant difference in the age or duration of symptoms between the 2 groups.

\section{Effect of SNRB on Back Pain}

The mean preinjection NRS score for back pain in the 42 patients who avoided surgery was 7.5 (SD 1.33) and reduced significantly to 3.1 (SD 1.69) $(P<0.001)$ within $30 \mathrm{~min}$ of the injection. The mean NRS score for back pain was 3.3 (SD 1.25), 3.2 (SD 1.74), and 2.4 (SD 1.27) at subsequent follow-up at 1 week, 3 weeks, and 3 months postinjection, respectively, which were significantly lower than the preinjection levels $(P$ $<0.0001$ ) (Figure 1). On the other hand, the 8 patients who underwent surgery also had significant pain relief in the initial period of follow-up; preinjection NRS score of 7.0 (SD 2.33) reduced to 4.5 (SD 1.93) within 30 min of injection and 2.8 (SD 2.49) and 2.5 (SD 1.73) at 1 and 3-week interval. However, these patients underwent surgery due to recurrence of severe leg pain before completion of 3 months.

\section{Effect of SNRB on Leg Pain}

The mean preinjection NRS score for leg pain was 7.7 (SD 1.35) and 8.3 (SD 0.71) and reduced to 2.3 (SD 1.14) and 3.0 (SD 2.33) $(P<0.005)$, respectively, within $30 \mathrm{~min}$ of the injection in patients who avoided the surgery and those who underwent surgery, respectively. Patients who avoided surgery had sustained pain relief at each subsequent visit. The NRS score for leg

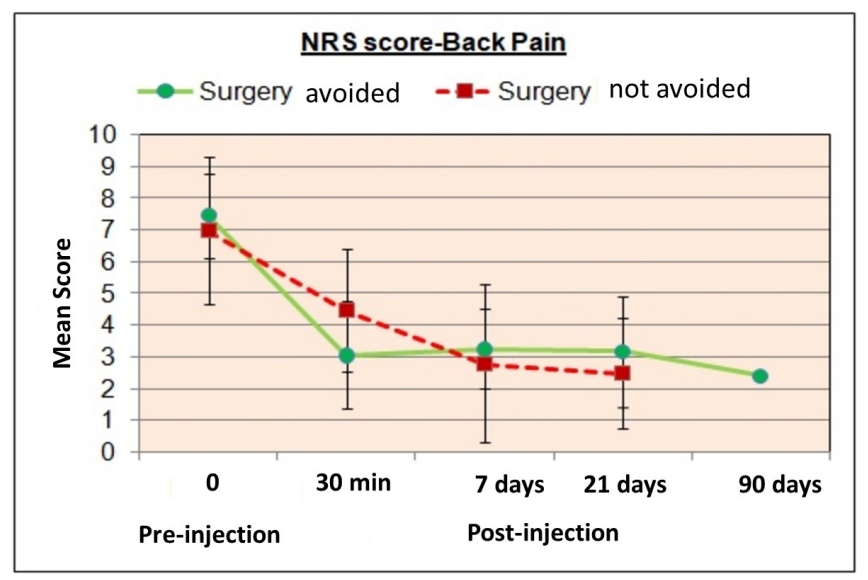

Figure 1. Temporal pattern of change in back pain intensity (numerical rating scale [NRS] score) in patients who avoided surgery and those who eventually underwent surgery after the administration of a selective nerve root block.

pain was 2.8 (SD 1.21), 2.6 (SD 1.60), and 2.0 (SD 1.47 ) at 1 week, 3 weeks, and 3 months postinjection, respectively, which was significantly less than compared to the preinjection mean NRS score $(P<0.001)$. However, the mean leg NRS pain score for patients who underwent surgery, showed an increasing trend at each follow-up (3.8 [SD 1.64] and 4.3 [SD 2.87] at 7 days and 3 weeks, respectively) after the initial reduction of pain (30 minutes after injection) (Figure 2).

\section{Effect of SNRB on Disability (ODI) Score}

The administration of an SNRB had a positive effect on disability associated with the back and leg pain as calculated using the ODI. The ODI score of 42 patients who avoided surgery reduced significantly from the preinjection level of 59.4 (SD 14.69) to 42.4 (SD 9.33), 38.6 (SD 11.99), and 26.3 (SD 9.43) $(P<0.001)$ at 1 week, 3 weeks, and 3 months postinjection, respectively. However, the ODI score of 8 patients who underwent surgery, despite showing an initial improvement, gradually increased and eventually 8 patients underwent surgery before completion of 3 months. The mean ODI score of these 8 patients was 66.9 (SD 15.5), 50.3 (SD 3.41), and 54 (SD 7.86), respectively, before injection and at 1 week and 3 weeks postinjection (Figure 3 ).

Table 2. Age and duration of symptoms among patients who avoided surgery and those who eventually underwent surgery after the administration of a selective nerve root block $(N=50)$.

\begin{tabular}{|c|c|c|c|c|c|c|c|c|}
\hline \multirow[b]{3}{*}{ Variable } & \multicolumn{8}{|c|}{ Surgery Avoided } \\
\hline & \multicolumn{4}{|c|}{ Yes } & \multicolumn{4}{|c|}{ No } \\
\hline & $n$ & Min & Max & Median & $n$ & Min & Max & Median \\
\hline Age, y & 42 & 19 & 69 & 43.0 & 8 & 27 & 72 & 36.0 \\
\hline Duration of symptoms, $\mathrm{d}$ & 42 & 1 & 60 & 14.0 & 8 & 7 & 30 & 15.0 \\
\hline
\end{tabular}




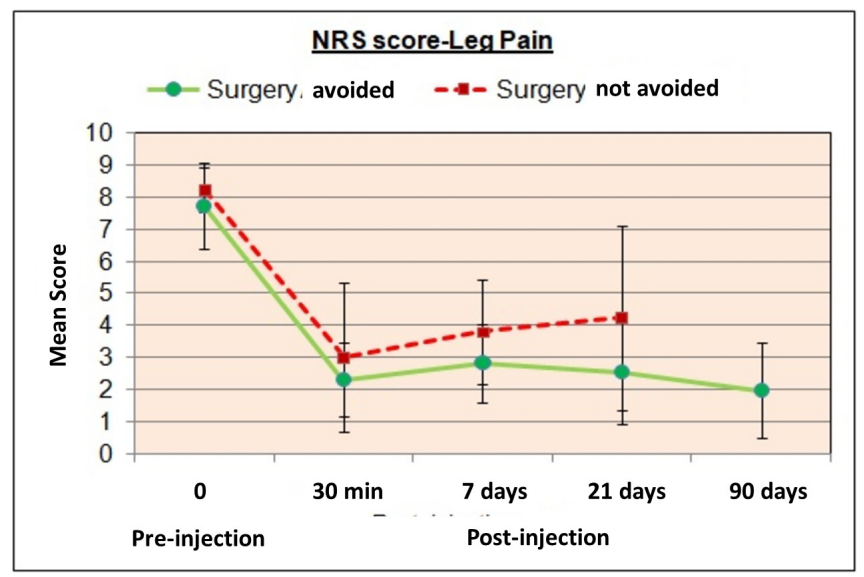

Figure 2. Temporal pattern of change in leg pain intensity (numerical rating scale [NRS] score) in patients who avoided surgery and those who eventually underwent surgery after the administration of a selective nerve root block.

\section{Effect of Depression, Anxiety, and Stress Lev- el on the Outcome of SNRB and the Need for Surgery}

The preinjection DASS-21 score of the 8 patients who eventually underwent the surgery showed a higher mean depression score than patients who were able to avoid surgery: 10.8 (SD 7.5) vs 5.3 (SD 4.3) $(P=$ $0.010)$. Although the mean anxiety and stress scores were also higher in patients who underwent surgery, the difference was not statistically significant (Table 3).

\section{DISCUSSION}

With the establishment of the role of inflammation in the pathogenesis of radicular pain, the use of corticosteroids to manage inflammation and alleviate pain has become a rational option with success rates ranging from $20 \%$ to $100 \%$ (average, $67 \%$ ). ${ }^{5,6,13,14}$

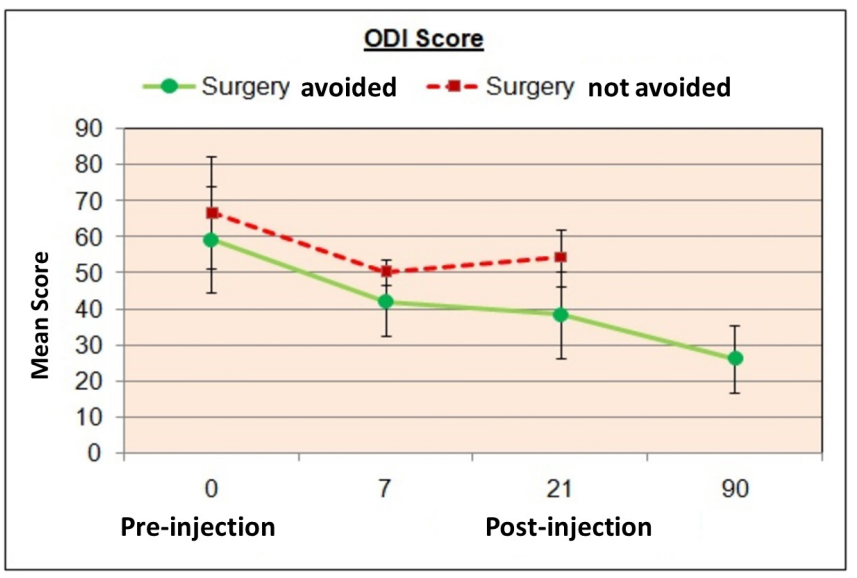

Figure 3. Graph showing temporal pattern of change in disability (Oswestry Disability Index [ODI] score) in patients who avoided surgery and those who eventually underwent surgery after the administration of a selective nerve root block.
The transforaminal route for administration of steroid around the inflamed nerve root was first popularized by Macnab in $1971 .{ }^{5}$ While there is a plethora of published literature available on the outcomes following SNRB/ transforaminal steroid injections for lumbar radiculopathy, the conclusions of many studies and reviews are contradictory. A systematic review by Manchikanti et $\mathrm{al}^{14}$ assessed the pain relief and functional improvement using 3 approaches (caudal, interlaminar, and transforaminal) of steroid administration in the treatment of disc herniation and found strong evidence of short-term efficacy ( $<6$ months) and moderate evidence of longterm efficacy ( $>6$ months). ${ }^{14}$ Similar outcomes have been described by some other published studies and meta-analysis. ${ }^{10,15,16}$ However, the presence of significant heterogeneity among trials has led to differing and often confusing conclusions. $^{7-9}$

A double-blinded randomized controlled trial found that of 55 patients requiring surgery for lumbar disc herniation, 29 (52\%) decided not to undergo surgery following an SNRB with minimum follow-up of 1 year with no recurrence of pain even after 5 years. ${ }^{10}$ Kanna et al $^{16}$ reported that $75 \%$ of 91 patients had good pain relief following an SNRB and were able to avoid surgery upto 1 year. ${ }^{16}$ In the present study, $42 / 50$ (84\%) patients were able to avoid surgery at 3-month follow-up following the administration of a single SNRB. The higher success rate in this study could be attributed to the early administration of SNRB (without the mandatory 6 -week trial of nonoperative treatment). In the present study, a single SNRB (steroid + local anesthetic) provides more than $50 \%$ relief of back and leg pain immediately (within $30 \mathrm{~min}$ ). The mean NRS score for back and leg pain in patients who avoided surgery reduced from a preinjection score of 7.5 (SD 1.33) and 7.7 (SD $1.35)$ to 3.1 (SD 1.69) and $2.3(1.14)(P<0.001)$ within 30 min following the injection. Even the mean back and leg NRS pain score of patients who underwent surgery, reduced from a preinjection level of 7.0 (SD 2.33) and 8.3 (SD 0.71) to 4.5 (SD 1.93) and 3.0 (SD 2.33), respectively, immediately after the injection. Although the instantaneous pain relief could be attributed to the local anesthetic agent, the pain relief was sustained over the next 3 months in a majority of patients (84\%) thus obviating the need for surgery. The ODI score of 42 patients who avoided the surgery reduced from the preinjection level of 59.4 (SD 14.69) to 26.3 (SD 9.43) ( $P$ $<0.001)$ at 3 months postinjection. The instantaneous and sustained effect of the nerve root block in reducing pain and disability reduces the duration of pain and suffering significantly. 
Table 3. Average depression, anxiety, and stress levels (DASS-21 score) among patients who avoided surgery and those who eventually underwent surgery after administration of a selective nerve root block $(\mathrm{N}=50)$.

\begin{tabular}{|c|c|c|c|c|c|}
\hline DASS-21 & Surgery Avoided & $\begin{array}{c}\text { Surgery } \\
\text { Not Avoided }\end{array}$ & CI Lower & CI Upper & $P$ Value \\
\hline Depression & $5.3 \pm 4.83$ & $10.8 \pm 7.25$ & 1.37 & 9.52 & 0.010 \\
\hline Anxiety & $3.3 \pm 3.56$ & $5.3 \pm 4.27$ & -0.88 & 4.81 & 0.172 \\
\hline Stress & $8.2 \pm 7.02$ & $12.5 \pm 7.07$ & -1.12 & 9.78 & 0.116 \\
\hline
\end{tabular}

Depression and anxiety are known to perpetuate the severity and chronicity of chronic back pain with poor response to physiotherapy and surgery. ${ }^{17,18}$ This study revealed that patients who underwent surgery had a higher mean depression score and did not respond to SNRB as favorably as those with lower scores who eventually avoided surgery (10.8 [SD 7.5] vs 5.3 [SD 4.3]) $(P=0.010)$. Although the mean anxiety and stress level was also higher in patients who underwent the surgery, the difference was not statistically significant. Psychological counseling and anxiety alleviation should be important components in the management of spinal pathologies.

Botwin et $\mathrm{al}^{19}$ reported minor complications in $17 / 207$ patients (322 injections) including nonpositional headache in 8 patients $(3.1 \%)$, increased back pain in 2 patients $(2.4 \%)$, increased leg pain in 4 patients $(0.6 \%)$, facial flushing in 1 patient $(1.2 \%)$, vasovagal reaction in 1 patient $(0.3 \%)$, and increased blood sugar in 1 diabetic patient $(0.3 \%) .{ }^{19}$ Major events, though very rare, include vascular embolic events causing spinal cord infarction, paraplegia, and death following inadvertent intra-arterial injection of particulate steroids. ${ }^{20,21}$ However, a majority of serious complications including death, cerebrovascular accident, meningitis, pneumocephalus, and pneumorrhachis have been reported following a cervical epidural injection. ${ }^{22-24}$ In this study, there were no major complications except transient lower limb numbness lasting a few hours after the injection.

One of the limitations of the study was the small number of patients. However, the results were similar to that reported in other studies ${ }^{10,16}$ and hence the result of this study can be extrapolated. The second limitation is short duration of follow-up. However, studies have shown that the initial benefits of an SNRB are sustained over a long period of time. ${ }^{10,15,16}$

\section{CONCLUSION}

SNRB is recommended in the early stages of lumbar radiculopathy as it provides instantaneous and sustained relief of back and leg pain and disability in a majority of patients, thereby reducing the duration of pain and suffering and obviates the need for surgery in a majority of patients. However, the presence of depression can negatively affect the outcome following SNRB, leading to persistent pain necessitating surgery.

\section{ACKNOWLEDGMENTS}

This research study was approved by institutional ethical committee and review board.

\section{REFERENCES}

1. Stafford MA, Peng P, Hill DA. Sciatica: a review of history, epidemiology, pathogenesis, and the role of epidural steroid injection in management. Br J Anaesth. 2007;99(4):461-473. doi:10.1093/ bja/aem 238

2. Mixter WJ, Barr JS. Rupture of the intervertebral disc with involvement of the spinal canal. NEngl J Med. 1934;211(5):210-215. doi:10.1056/NEJM193408022110506

3. Weber H. Lumbar disc herniation. A controlled, prospective study with ten years of observation. Spine (Phila Pa 1976). 1983;8(2):131-140

4. Saal JA, Saal JS. Nonoperative treatment of herniated lumbar intervertebral disc with radiculopathy. Spine. 1989;14(4):431-437. doi:10.1097/00007632-198904000-00018

5. Macnab I. Negative disc exploration. An analysis of the causes of nerve-root involvement in sixty-eight patients. $J$ Bone Joint Surg Am. 1971;53(5):891-903

6. Tajima T, Furukawa K, Kuramochi E. Selective lumbosacral radiculography and block. Spine. 1980;5(1):68-77. doi:10.1097/00007632-198001000-00013

7. Bhatia A, Flamer D, Shah PS, Cohen SP. Transforaminal epidural steroid injections for treating lumbosacral radicular pain from herniated intervertebral discs: a systematic review and meta-analysis. Anesth Analg. 2016;122(3):857-870. doi:10.1213/ ANE.0000000000001155

8. Quraishi NA. Transforaminal injection of corticosteroids for lumbar radiculopathy: systematic review and meta-analysis. Eur Spine J. 2012;21(2):214-219. doi:10.1007/s00586-011-2008-y

9. Karppinen J, Malmivaara A, Kurunlahti M, et al. Periradicular infiltration for sciatica: a randomized controlled trial. Spine (Phila Pa 1976). 2001;26(9):1059-1067. doi:10.1097/00007632200105010-00015

10. Riew KD, Park J-B, Cho Y-S, et al. Nerve root blocks in the treatment of lumbar radicular pain. A minimum five-year follow-up. J Bone Joint Surg Am. 2006;88(8):1722-1725. doi:10.2106/ JBJS.E.00278

11. Bogduk N. Clinical Anatomy of the Lumbar Spine and SacrumClinical Anatomy of the Lumbar Spine and Sacrum. Churchill Livingstone; 1997:127-144 
12. Derby R, Bogduk N, Kine G. Precision percutaneous blocking procedures for localizing spinal pain. Part 2. The lumbar neuraxial compartment. Pain digest. 1993;3:175-188

13. Bogduk N, Brazenor G, Christophides N, et al. Epidural Use of Steroids in the Management of Low Back Pain and Sciatica of Spinal Origin: Report of the Working ParEpidural Use of Steroids in the Management of Low Back Pain and Sciatica of Spinal Origin: Report of the Working Party. National Health and Medical Research Council; 1993:102-106

14. Manchikanti L, Buenaventura RM, Manchikanti KN, et al. Effectiveness of therapeutic lumbar transforaminal epidural steroid injections in managing lumbar spinal pain. Pain Phys. 2012;3;15(3;5):E199-E245. doi:10.36076/ppj.2012/15/E199

15. DePalma MJ, Bhargava A, Slipman CW. A critical appraisal of the evidence for selective nerve root injection in the treatment of lumbosacral radiculopathy. Arch Phys Med Rehabil. 2005;86(7):1477-1483. doi:10.1016/j.apmr.2005.01.006

16. Kanna RM, Shetty AP, Rajasekaran S. Predictors of successful outcomes of selective nerve root blocks for acute lumbar disc herniation. Global Spine J. 2019;9(5):473-479. doi:10.1177/2192568218800050

17. Magni G, Caldieron C, Rigatti-Luchini S, Merskey H. Chronic musculoskeletal pain and depressive symptoms in the general population. An analysis of the 1st National Health and Nutrition Examination Survey data. Pain. 1990;43(3):299-307. doi:10.1016/0304-3959(90)90027-B

18. Sinikallio S, Aalto T, Airaksinen O, Herno A, Kröger H, Viinamäki H. Depressive burden in the preoperative and early recovery phase predicts poorer surgery outcome among lumbar spinal stenosis patients. Spine. 2009;34(23):2573-2578. doi:10.1097/ BRS.0b013e3181b317bd

19. Botwin KP, Gruber RD, Bouchlas CG, Torres-Ramos FM, Freeman TL, Slaten WK. Complications of fluoroscopically guided transforaminal lumbar epidural injections. Arch Phys Med Rehabil. 2000;81(8):1045-1050. doi:10.1053/apmr.2000.7166

20. Houten JK, Errico TJ. Paraplegia after lumbosacral nerve root block: report of three cases. Spine J. 2002;2(1):70-75. doi:10.1016/s1529-9430(01)00159-0

21. Kennedy DJ, Dreyfuss P, Aprill CN, Bogduk N. Paraplegia following image-guided transforaminal lumbar spine epidural steroid injection: two case reports. Pain Med.2009;10(8):1389-1394. doi:10.1111/j.1526-4637.2009.00728.x
22. Ziai WC, Ardelt AA, Llinas RH. Brainstem stroke following uncomplicated cervical epidural steroid injection. Arch Neurol. 2006;63(11):1643-1646. doi:10.1001/archneur.63.11.1643

23. Windsor RE, Storm S, Sugar R, Nagula D. Cervical transforaminal injection: review of the literature, complications, and a suggested technique. Pain Physician. 2003;6(4):457-465

24. De Oliveira GS, Charchaflieh J, Walega D. Pneumorrhachis mimicking meningitis after a paramedian lumbar interlaminar injection. Clin J Pain. 2011;27(4):355-356. doi:10.1097/AJP.0b013e3181f1eabb

Funding: The authors received no financial support for the research, authorship, and/or publication of this article.

Declaration of Conflicting Interests: The authors declared no potential conflicts of interest with respect to the research, authorship, and/or publication of this article.

Patient Consent for Publication: We authors certify that we have obtained all appropriate patient consent forms, in which the patients gave their consent for their clinical information to be reported in the journal. The patients understand that their names and initials will not be published and due efforts will be made to conceal their identity, but anonymity cannot be guaranteed.

Corresponding Author: Thomas J. Kishen, Consultant Spine Surgeon, Spine Care Centre, Manipal Hospital, Bangalore, India; thomas.kishen@manipalhospitals.com

Published 20 January 2022

This manuscript is generously published free of charge by ISASS, the International Society for the Advancement of Spine Surgery. Copyright (C) 2022 ISASS. To see more or order reprints or permissions, see http:// ijssurgery.com. 